\title{
Seroprevalencia de la enfermedad de Chagas y factores de riesgo asociados en una población de Morroa, Sucre
}

\author{
Richard Hoyos ', Lisandro Pacheco ", Luz Adriana Agudelo 2, German Zafra 3, Pedro Blanco 1, \\ Omar Triana ${ }^{2}$ \\ 1 Grupo de Investigaciones Biomédicas, Universidad de Sucre, Sincelejo, Sucre, Colombia. \\ ${ }^{2}$ Grupo de Chagas, Universidad de Antioquia, Medellín, Colombia. \\ ${ }^{3}$ Grupo de Inmunología y Epidemiología Molecular, Universidad Industrial de Santander, \\ Bucaramanga, Colombia.
}

Introducción. La enfermedad de Chagas constituye un grave problema de salud publica en Latinoamérica; en Colombia existen en gran parte de su geografía las condiciones ecoepidemiológicas propicias para la transmisión activa de esta enfermedad.

Objetivo. En este estudio fue evaluada una población del municipio de Morroa, departamento de Sucre, para identificar factores de riesgo y determinar la seroprevalencia a la enfermedad de Chagas.

Materiales y métodos. A una muestra de 122 personas pertenecientes al área rural $(n=76)$ y urbana $(n=46)$, se les aplicó una encuesta epidemiológica y se les realizó un tamizaje serológico con la prueba Elisa, confirmación de seropositivos con hemoaglutinación indirecta (HAI) (Chagatest®) y reacción en cadena de la polimerasa (PCR) como prueba parasitológica confirmatoria.

Resultados. Cuatro de las personas resultaron positivas para Elisa (3,28\%); sin embargo, fueron negativas a HAI y PCR. La serología discordante fue definida con prueba de inmunofluorescencia indirecta (IFI), encontrándose una de las cuatro personas positivas. La población analizada mostró una baja presencia de anticuerpos anti-Trypanosoma cruzi. No fue posible determinar la presencia del parásito en sangre usando la prueba PCR. Los principales factores de riesgo presentes fueron casas con techos de palmas, piso de tierra, paredes de bahareque y madera, y la presencia de reservorios (animales domésticos).

Conclusiones. Nuestros resultados indican que la zona estudiada presenta elementos de riesgo para el establecimiento de un ciclo de transmisión activa, se hace necesario verificar la presencia de triatominos en la zona de estudio y establecer medidas para prevenir la presencia de la enfermedad de Chagas en el área de Morroa, Sucre.

Palabras claves: Trypanosoma cruzi, enfermedad de Chagas, serología, factores de riesgo, prueba de Elisa, epidemiología.

Seroprevalence of Chagas disease and associated risk factors in a population of Morroa, Sucre

Introduction. Chagas disease is a major public health problem in Latin America. In Colombia, a large area has the ecoepidemiological conditions which favor the active transmition of this infection.

Objective. This study was undertaken in a population from the municipality of Morroa, Sucre Province, to evaluate risk factors and to determine the seroprevalence to Chagas disease.

Materials and methods. A questionnaire was given to a sample population of 122 people classed as rural $(n=76)$ or urban area $(n=46)$. A serological screening was undertaken by Elisa test, with confirmation of seropositives with IHA (Chagatest $\left.{ }^{\circledR}\right)$ and parasitological confirmation by polymerase chain reaction (PCR).

Results. Four people were positive by Elisa test (3.3\%); however, they were negative by IHA and PCR. One of the four positives by Elisa was positive by indirect immuno flourescence (IFAT) as well. The sample showed a low presence of seropositives against Trypanosoma 
cruzi. However, the presence of parasite could not be confirmed by the PCR test. The main risk factors were houses thatched with palm roofs, clay floors, wood walls, and presence of domestic animal reservoirs.

Conclusions. The study population presented risk factors for the establishment of active transmission. The presence of triatomines must be verified in this area and establishment of control measures are necessary for preventiving the resurgence of the Chagas disease in Morroa.

Key words: Trypanosoma cruzi, Chagas disease, serology, risk factors, Elisa test, epidemiology.

Trypanosoma cruzi, agente causal de la enfermedad de Chagas, es transmitido por insectos vectores de la subfamilia Triatominae. La fase crónica de la enfermedad se caracteriza por complicaciones cardíacas y digestivas (1). Los datos serológicos indican que alrededor de 17 a 24 millones de latinoamericanos se encuentran infectados y cerca de 120 millones están en riesgo de infectarse (2). En Colombia se ha estimado que un $5 \%$ de la población puede estar infectada y un $23 \%$ se encuentra en zona de alto riesgo (3).

Las principales condiciones para el establecimiento de la enfermedad de Chagas en las zonas de riesgo son la presencia del insecto vector, los animales silvestres que sirvan de reservorios, la circulación del parásito y las condiciones socioeconómicas de la región (tipo de vivienda, hacinamiento y presencia de animales domésticos que facilitan la transmisión activa de T. cruzi) (4).

Las condiciones biológicas, ecológicas y ambientales del territorio nacional favorecen los ciclos ecoepidemiológicos del parásito, lo que hace necesario realizar encuestas serológicas para conocer la proporción de individuos infectados en las zonas geográficas del país.

Para estos estudios epidemiológicos se utilizan los métodos serológicos convencionales: inmunoensayo ligado a una enzima (Elisa), hemoaglutinación indirecta $(\mathrm{HAl})$ e inmunofluorescencia indirecta (IFI) para detectar la presencia de anticuerpos contra $T$. cruzi, $(4,5)$.

Correspondencia:

Richard Hoyos Lopez; Carrera $14 \mathrm{~N}^{\circ} 16 \mathrm{~B}$ - 32, Laboratorio de Investigaciones Biomédicas, Sincelejo, Sucre, Colombia. Teléfono: (055) 2820830; fax: (055) 2823867.

richard_hoyoslopez@yahoo.com

Recibido: 02/02/06; aceptado: 16/08/06
Cuando se desea determinar la presencia del parásito $T$. cruzi en sangre circulante, la reacción en cadena de la polimerasa (PCR) constituye una importante herramienta que de alguna manera reemplaza las técnicas de microscopía existentes (6).

La presencia de vectores triatominos en el departamento de Sucre (7), la falta de datos relacionados con la epidemiología y los factores de riesgo para la enfermedad de Chagas en la región motivaron el presente estudio de una muestra poblacional del municipio de Morroa, Sucre, considerado de bajo riesgo (8), con el fin de determinar la seroprevalencia de la enfermedad de Chagas con métodos serológicos convencionales y evaluar los factores de riesgo asociados.

\section{Materiales y métodos}

\section{Localidad y población de estudio}

El estudio se llevó a cabo en el municipio de Morroa (coordenadas geográficas: $9^{\circ} 28^{\prime}$ norte, $9^{\circ}$ $18^{\prime}$ sur, $75^{\circ} 15^{\prime}$ este y $75^{\circ} 21^{\prime}$ oeste, departamento de Sucre), situado a 150 metros sobre el nivel del mar en la costa Atlántica de Colombia, con una temperatura promedio de $27^{\circ} \mathrm{C}$ y predominio de clima de sabana tropical y vegetación principalmente compuesta de palmas y áreas boscosas. La población es de 16.120 personas, de las cuales el $68 \%$ pertenece al área rural. La muestra poblacional fue calculada basándose en el programa estadístico Epi info 2003, utilizando un promedio de prevalencia de la enfermedad de Chagas del $5 \%$, la población del municipio y un nivel de confianza del $95 \%$.

\section{Muestras}

Las personas que participaron en el estudio debían pertenecer al área de Morroa y tener un periodo de permanencia en la zona mayor a cinco años, 
las personas que no cumplían con estos criterios no fueron tenidas en cuenta para la realización del estudio. Previa firma de consentimiento informado, las personas respondieron una encuesta epidemiológica y se extrajo una muestra de sangre que fue dividida en dos viales: uno para extracción de suero y uno con anticoagulante (EDTA - 0,2 M, pH = 8,0) para extracción de ADN. Las muestras de sangre y suero se recolectaron en el Laboratorio Clínico del Centro Médico de Salud San Blas del 2 de septiembre al 3 diciembre del 2004, y correspondieron a 122 personas asentadas en 117 viviendas del área rural y urbana.

\section{Encuesta epidemiológica}

Las variables tomadas en cuenta fueron el tipo de vivienda; el conocimiento sobre el vector, para lo cual a cada persona participante en el estudio se le mostraron ejemplares adultos y ninfales de Triatoma maculata; los lugares de avistamiento del insecto, los tipos de animales domésticos y el hacinamiento. Se realizó una búsqueda pasiva de vectores, para lo cual se distribuyeron viales plásticos rotulados estériles en el corregimiento de Las Flores. Estos datos se procesaron en el programa estadístico Epi Info 2003.

\section{Ensayos serológicos}

La Organización Mundial de la Salud (OMS) recomienda que las muestras de suero sean clasificadas como positivas para la enfermedad de Chagas si son reactivas a dos de tres técnicas serológicas con metodologías diferentes (2). En este trabajo se utilizaron como pruebas diagnósticas Elisa, HAI e IFI.

La prueba de Elisa se desarrolló de acuerdo al protocolo descrito por Gea et al. (1987) y Takasu et al. (1989) (9,10); el ensayo se realizó en microplacas Nunc - Immuno Plate (Maxisorp surface) y un lector de Elisa Biorad (model 550). El antígeno consistió en un extracto crudo de epimastigotes de T. cruzi (cepa Y), el cual se adicionó a una concentración de 1,22 uglml e incubado 24 horas en buffer carbonato $(\mathrm{pH}=9,6)$. Los sueros se utilizaron en diluciones de 1:800 y como conjugado enzimático se utilizó antiinmunoglobulina $\mathrm{G}$ ligada a fosfatasa alcalina en dilución de 1:1000. El sustrato $p$-nitrofenilfosfato
(Sigma \# catalogo 104) se adicionó a una concentración de $1 \mathrm{mg} / \mathrm{ml}$ para ser leída a una longitud de onda de $410 \mathrm{~nm}$ después de agregar 50 ul de $\mathrm{NaOH} 3 \mathrm{~N}$. Se consideraron muestras reactivas positivas aquellas cuya D.O fuera mayor al punto de corte (punto de corte $=0,300$ ).

\section{Hemoaglutinación indirecta}

Esta prueba se realizó con el kit Chagatest ${ }^{\circledR}$ (Wiener Lab) y se consideraron reactivas las muestras con títulos iguales o mayores a 1:32.

\section{Inmunofluorescencia indirecta}

En esta prueba se utilizaron como antígeno proteínas formalizadas totales de epimastigotes de la cepa HA de T. cruzi de Colombia, y como anticuerpo, un anti IgG humano marcado con isotiocianato de fluoresceína (FITC), según el protocolo establecido en el laboratorio de Chagas de la Universidad de Antioquia (11). El punto de corte se estableció a partir de la segunda dilución (1:40).

\section{Extracción de ADN y PCR}

El protocolo de extracción empleado es el descrito por Sambrook et al. (1989) (12): $500 \mu \mathrm{L}$ de sangre se mezclaron con buffer de lisis $2 \mathrm{X}$ (Tris - $\mathrm{HCl} 10$ $\mathrm{mM} \mathrm{PH}=7,4$; EDTA $5 \mathrm{M}$ a $\mathrm{pH}=8,0$; SDS al $1 \%$ ) y $10 \mu \mathrm{L}$ de proteinasa $\mathrm{K}(20 \mathrm{mg} / \mathrm{ml})$; se incubaron a $55^{\circ} \mathrm{C}$ por 1 hora y después toda la noche a $37^{\circ} \mathrm{C}$; luego se inactivó la proteinasa $\mathrm{K}$ (5 minutos a $95^{\circ} \mathrm{C}$ ) para centrifugar a 12.000 r.p.m por 40 minutos; el sobrenadante resultante se tomó para la extracción del ADN con sales de alta molaridad. El sobrenadante de ADN se resuspendió en 50 $\mu \mathrm{L}$ de buffer TE $1 \mathrm{X}$, almacenándose luego a $-20^{\circ} \mathrm{C}$ hasta su uso.

En la prueba de PCR se usaron los iniciadores S35 (5'AAA TAA TGT ACG GGT GAG ATG CAT G 3') y $S 36$ (5‘GGG TTC GAT TGG GGT TGG $\left.T G 3^{\prime}\right)$, que amplifican un fragmento de $330 \mathrm{bp}$ de las regiones variables de minicírculos del kDNA de $T$. cruzi. La reacción de amplificación se realizó según Moser et al. (1989) (13) así: $2 \mu \mathrm{L}$ de buffer PCR (10X), 0,4 $\mu \mathrm{L}$ de dNTPs mezclados (200 $\mathrm{mM}), 1,2 \mu \mathrm{L}$ de $\mathrm{MgCl}_{2}(1,5 \mathrm{mM}), 1,2 \mu \mathrm{L}$ de cada iniciador $(0,6 \mathrm{mM}), 0,2 \mu \mathrm{L}$ de Taq polimerasa y $6 \mu \mathrm{L}$ de ADN problema, para un volumen final de 
$25 \mu \mathrm{L}$. La PCR se llevó a cabo en un termociclador PCR - Express (Hybaid) en las siguientes condiciones: 1 ciclo a $94^{\circ} \mathrm{C}$ (5 minutos), 35 ciclos a $94^{\circ} \mathrm{C}$ ( 1 minuto) $65^{\circ} \mathrm{C}$ ( 1 minuto) $72^{\circ} \mathrm{C}$ ( 1 minuto), y una extensión final a $72^{\circ} \mathrm{C}$ (10 minutos). Los productos amplificados se sometieron a una electroforesis en gel de agarosa al $1,8 \%$ y se visualizaron bajo luz U.V después de la tinción con bromuro de etidio.

\section{Consideraciones éticas}

El Comité de Investigaciones de la Facultad de Educación y Ciencias de la Universidad de Sucre aprobó este estudio.

\section{Resultados}

La encuesta epidemiológica reveló que en la muestra poblacional estudiada $(n=122)$, las condiciones socioeconómicas de la vivienda fueron uno de los factores de riesgo encontrados con mayor frecuencia. Los tipos de vivienda correspondieron principalmente a tres categorías: la combinada (62 viviendas, 50,9\%), que presenta por lo menos un elemento estructural de riesgo para la infestación por triatominos; en segundo lugar tenemos el "rancho"(37 viviendas, 30,3\%), que presenta todos los elementos estructurales de riesgo para la infestación por vectores de la enfermedad de Chagas y, por último, la casa de material $(18,8 \%)$.

Los animales domésticos encontrados en la mayoría de las viviendas de la población encuestada fueron perros (Canis familiaris, $57,2 \%$ ), gallinas (Gallus gallus, $44,4 \%$ ) y cerdos (Sus scropha, 36,7\%), presentándose convivencia de diferentes especies dentro de la misma casa.

El hacinamiento fue un factor presente en el $83,6 \%$ de los domicilios encuestados, ya que presentaban cinco o más personas por habitación en el domicilio.

Las personas que manifestaron conocer el vector después de ver ejemplares adultos y ninfales de T. maculata fueron $54(44,2 \%)$, siendo las paredes de las habitaciones el lugar más frecuente de observación y los dormitorios el sitio predilecto para la alimentación de los triatominos (34 y 44\%, respectivamente). La búsqueda pasiva de vectores en el corregimiento de Las Flores fue negativa.

El análisis por Elisa reveló cuatro personas seropositivas, un hombre y tres mujeres que se encontraban en el grupo de edad entre los 14 y 45 años. A los sueros seropositivos se les realizó una prueba de HAI con el estuche Chagatest ${ }^{\circledR}$ (Wiener Lab) con resultados negativos. Dada la discrepancia que existía en cuanto al estado serológico de estos cuatro individuos (Elisa +, HAI -), se definió la seropositividad con el ensayo de IFI, el cual dio resultado positivo en una de las cuatro muestras, con un título de 1:40.

La amplificación del kDNA de T. cruzi por PCR en las muestras de sangre pertenecientes a individuos seropositivos por Elisa y positivos para IFI fue negativa.

\section{Discusión}

En el ciclo silvestre los triatominos están ubicados en ecotopos con unas características particulares dependiendo del género Triatominae al que pertenezcan; así, las especies pertenecientes a Rhodnius se han encontrado asociadas principalmente a palmas $(14,15)$; Panstrongylus $s p$. se encuentra en cavidades y huecos de palmas, en árboles y también en madrigueras de vertebrados silvestres (16); Triatoma $s p$. frecuentemente se localiza en hábitats rocosos y madrigueras de roedores (16). Los diferentes nichos ecológicos colonizados por las especies Triatominae se distribuyen de acuerdo a la asociación que presentan en el ambiente silvestre y las preferencias de sustrato se reflejan en los sitios infestados por los triatominos dentro de las casas (14); por esta razón, se considera que uno de los factores de riesgo mas relevantes es el tipo de construcción de los domicilios. En la población estudiada, la mayor parte de las viviendas presentaban por lo menos un elemento estructural de riesgo para la infestación por triatominos $(50,9 \%)$, y otro porcentaje $(30,3 \%)$ presentaba todos los elementos estructurales de riesgo para la infestación por vectores de la enfermedad de Chagas, ya que las viviendas con paredes de bahareque y techos de palma presentan los micrositios (fisuras) y microclimas que permiten una domiciliación acelerada de 
triatominos por tener una temperatura y humedad similares a las de los silvestres (17).

Aunque se considera que las casas con elementos materiales sólidos (bloque, cemento y tejas de asbesto-cemento, presentes en un $18,8 \%$ ) no presentan ningún tipo de riesgo, se ha observado que algunas especies como $T$. maculata y $T$. dimidiata, presentes en Colombia y la Costa Atlántica $(14,15,18)$, tienen una presencia ligada al hacinamiento y no a estructuras de riesgo, considerándose la presencia de estas especies vectoras un factor de riesgo para cualquier tipo de vivienda $(15,19)$. El hacinamiento fue del $83,6 \%$, lo que indica que había casas con dos habitaciones y cinco o más habitantes; además, las características de higiene asociadas con el hacinamiento se consideran como de riesgo para la transmisión vectorial $(19,20)$, la infestación, y también para la picadura de los triatominos a individuos, ya que facilitan una mayor concentración de fuentes de alimentos en un mínimo de espacio.

Los principales animales domésticos encontrados coinciden con los reservorios caracterizados para $T$. cruzi y con otras experiencias epidemiológicas, en las que se han encontrado fuertes asociaciones entre cerdos y la especie Panstrongylus geniculatus (21), y entre gallinas y $T$. dimidiata, $T$. maculata y Rhodnius prolixus $(3,15,22)$. Hay que resaltar que existen reportes que asocian la presencia de especies de triatominos infectados con tripanosomas en los municipios del departamento de Sucre $(7,23,24)$.

Los perros son los reservorios principales para $T$. cruzi y los tres principales géneros de Triatominae tienen como fuente fundamental de alimento a esta especie. La presencia de posibles fuentes de alimentos susceptibles de ser reservorios está ligada a altas densidades de animales domésticos que duermen en el intradomicilio y peridomicilio, además de la presencia de diferentes especies de animales en la vivienda, como se observó en la muestra poblacional estudiada, en la que además de los tres reservorios antes mencionados, se encontraron patos (Anas sp), pavos (Meleagris gallipavo), gatos (Felis catus), burros (Equus asinus), vacas (Bos taurus), lo que aumenta la densidad de animales en los domicilios estudiados y facilita a los insectos vectores la obtención de alimento.

Se realizó una búsqueda pasiva en los domicilios del corregimiento de Las Flores (Morroa, Sucre), después de realizar actividades de educación sobre los peligros de la enfermedad de Chagas y el vector Triatominae; esta búsqueda arrojó resultados negativos, pues no se encontraron ejemplares de triatominos, aunque sí hay antecedentes de infestación años atrás, según informaciones anecdóticas de los moradores de este corregimiento. No se descarta la presencia de vectores en el área de este municipio, debido a que el principal tipo de vegetación son las palmas en el peri y extradomicilio, y en el departamento de Sucre, Poyet (1995) (24) y Agudelo (2005) (Agudelo L. Experiencias epidemiológicas del Grupo de Chagas, Universidad de Antioquia. En: Jaramillo N, Parra G, Triana O, Moreno J, editores. Memorias del VIII Curso Internacional sobre la Ecoepidemiología de la Enfermedad de Chagas y sus Métodos de Estudio. Medellín: Editorial Gráficas; 2005) reportan infestación con triatominos ( $R$. pallescens, $T$. dimidiata y $P$. geniculatus) en palmas del género Attalea (Attalea butyracea, "palma de vino"), Scheelea y Cocos (Cocos nucifera, "palma de coco").

Las pruebas serológicas constituyen importantes herramientas que permiten estimar los niveles de infección por T. cruzi y evaluar medidas de control epidemiológico y vectorial (20). Sin embargo, la persistencia de resultados falsos debidos a la gran cantidad de reacciones cruzadas con anticuerpos de individuos que padecen otras enfermedades parasitarias relacionadas (4) ha llevado a la OMS a recomendar el uso de por lo menos dos técnicas serológicas con fundamentos metodológicos diferentes $(2,4,5)$. En nuestro estudio, la prueba Elisa para detectar niveles de IgG anti-T. cruzi fue lo suficientemente sensible en los sueros de la población estudiada, discriminando cuatro muestras reactivas cuya densidad óptica fue mayor al punto de corte y no se ubicaron dentro de la zona gris $(0,270$ a 0,330$)$.

Al realizar la prueba de HAl con el estuche Chagatest ${ }^{\circledR}$, las cuatro muestras resultaron 
negativas, resultado similar al obtenido por Cárdenas et al.(2002), quien obtuvo seis muestras reactivas por Elisa y todas negativas por Chagatest $\AA^{\circledR}$, lo que demuestra la discordancia entre esta prueba y Elisa (25). Hay que destacar que el kit Chagatest ${ }^{\circledR}$ utiliza antígeno citoplasmático liofilizado de cepas argentinas, por lo que podría explicarse que las muestras no reaccionen debido a la posible diferencia en determinantes antigénicos entre las cepas del cono sur y las cepas de $T$. cruzi colombianas. Esta hipótesis es expuesta por Enciso et al. (2004), quienes, para explicar las discordancias que existen al tamizar muestras por Elisa y estuches de HAI foráneos, además proponen aspectos relacionados con el estadio del parásito utilizado como antígeno, su preparación, el ciclo de transmisión al que pertenece la cepa aislada, así como el huésped o reservorio de origen (26). Estos sueros también se analizaron con la técnica de IFI, y se confirmó una de las cuatro muestras como positiva para $T$. cruzi, encontrándose el primer caso autóctono de la enfermedad de Chagas en un municipio considerado de bajo riesgo, en el cual no se ha reportado la presencia de individuos infectados por T. cruzi.

La PCR se realizó con el objetivo de detectar la presencia del parásito en sangre; tres muestras fueron negativas por ausencia de infección (positivos para Elisa, negativos para Chagatest ${ }^{\circledR}$ e IFI), y una muestra fue negativa por ausencia de parasitemia en sangre periférica (positivo para Elisa e IFI, negativo para Chagatest ${ }^{\circledR}$ ); este resultado es consistente con el de personas en estado latente o crónico de la enfermedad de Chagas, que presentan serología positiva pero escasa presencia de parásitos en sangre $(6,27)$; otras posibles causas que pueden incidir en los resultados son el tipo de extracción de ADN utilizado y el volumen de sangre usado en la extracción. Marcon et al (2002) desarrollaron una PCR anidada para detectar T. cruzien pacientes en estado crónico de la enfermedad (28); sin embargo, la alta sensibilidad encontrada con esta técnica es consecuencia de la alta parasitemia de las cepas procedentes de las áreas endémicas brasileñas, característica diferente a la de los aislamientos colombianos. En este sentido,
Morroa es considerada un área de bajo riesgo no endémica para la enfermedad de Chagas.

En conclusión, la zona de estudio presentó los elementos de riesgo estructurales con los ecotopos artificiales propicios para la infestación de triatominos; la convivencia con diferentes tipos de animales domésticos facilita una fuente de alimento estable y reservorios para el desarrollo de colonias domiciliadas de triatominos y, en consecuencia, la transmisión activa de $T$. cruzi. Por la prevalencia de $1,22 \%$ encontrada en la muestra estudiada se recomienda realizar estudios para ubicar la presencia de vectores triatominos y su índice de infección natural en los corregimientos y veredas pertenecientes al municipio de Morroa, así como establecer el estado seroepidemiológico de poblaciones pertenecientes al corregimiento de Tumbatoro (Morroa, Sucre), sitio de origen del individuo positivo por Elisa e IFI en este estudio.

\section{Conflicto de intereses}

Los autores manifiestan no tener conflictos de intereses con respecto a los resultados de esta investigación.

\section{Financiación}

Este trabajo de investigación pertenece a la línea de investigaciones biomédicas de la Universidad de Sucre y fue financiado parcialmente por el proyecto 1102-04-12901 registrado en Colciencias, así como con recursos del Laboratorio de Investigaciones Biomédicas de la Universidad de Sucre y el Grupo de Chagas de la Universidad de Antioquia.

\section{Referencias}

1. Atias A. Parasitología médica. Santiago de Chile: Publicaciones Técnicas Mediterráneas Ltda.: 1999. p. 251-64.

2. World Health Organization. Control of Chagas disease. Second Report of the WHO Expert Committee. Technical reports series 905. Geneva: WHO; 2002.

3. Moncayo A. Chagas disease: current epidemiological trends after the interruption of vectorial and transfusional transmission in the southern cone countries. Mem Inst Oswaldo Cruz 2003;98:577-91.

4. Cannova D, Aguilar M, Pacheco M, Simona M, Medina M. Validación del inmunoensayo enzimático 
(Elisa) y hemoaglutinación indirecta ( $\mathrm{HAl}$ ) para el serodiagnóstico de la enfermedad de Chagas. Salus 2002;6:4-9.

5. Gutierrez R, Angulo VM, Tarazona Z, Britto M, Fernandez $\mathbf{O}$. Comparison of four serological tests for the diagnosis of Chagas disease in a Colombian endemic area. Parasitology 2004;129:439-44.

6. Kirchhoff LV, Votava JR, Ochs DE, Moser DR. Comparison of PCR and microscopic methods for detecting Trypanosoma cruzi. J Clin Microbiol 1996;34:1171-5.

7. Molina JA, Gualdron LE, Brochero HL, Olano VA, Barrios D, Guhl F. Distribución actual e importancia epidemiológica de las especies de triatominos (Reduviidae: Triatominae) en Colombia. Biomédica 2000;20:344-60.

8. Guhl F, Restrepo M, Angulo VM, Antunes CM, Campbell-Lendrum D, Davies C. Lessons from a national survey of Chagas disease transmission risk in Colombia. Trends Parasitol 2005;21:259-62.

9. Gea S, Rodriguez P, Vottero-Cima E. Characterization of Trypanosoma cruzi antigens recognized by sera from patients with chronic Chagas disease. Int Archs Allergy Appl Immun 1987;84:410-3.

10.Takasu N, Masuko T, Hojo H, Hashimoto Y. A microplate-immunofluorescence assay for antiTrypanosoma cruzi antibodies. Tohoku J Exp Med 1989;159:307-12.

11. Agudelo L. Ecoepidemiología de la enfermedad de Chagas en la cuenca del Río Palomino, Sierra Nevada de Santa Marta. (Tesis de maestría) Medellín: Universidad de Antioquia; 2006.

12. Sambrook J, Fritsh E, Maniatis T. Molecular cloning. A laboratory manual. New York: Cold Spring Harbor Laboratory; 1989. p.223-45.

13. Moser D, Kirchhoff L, Donelson J. Detection of Trypanosoma cruzi by DNA amplification using the polymerase chain reaction. J Clin Microbiol 1989;27:1477-82.

14. Lent $\mathbf{H}$, Wigodzinsky $\mathbf{P}$. Revision of the Triatominae (Hemiptera, Reduviidae), and their significance as vectors of Chagas disease. Bull Am Mus Nat Hist 1979;163:123-520.

15. Márquez J, Palencia J. Detección de Trypanosoma cruzi en una población de triatominos (Triatoma maculata) en Córdoba, Bolívar. (Tesis de grado). Sincelejo: Universidad de Sucre; 2004.

16. Gaunt M, Miles M. The ecotopes and evolution of Triatomine bugs (Triatominae) and their associated trypanosomes. Mem Inst Oswaldo Cruz 2000;95:557-65.

17. Pizarro JC, Romaña C. Variación estacional de una población silvestre de Rhodnius pallescens
(Heteroptera: Triatominae) BARBER 1932 en la costa Caribe colombiana. Bull Inst Fr Etudes Audines 1998;27:309-25

18. Cortés L, Suárez H. Triatominos (Reduviidae: Triatominae) en un foco de enfermedad de Chagas en Talaigua Nuevo (Bolívar, Colombia). Biomédica 2005;25:568-74

19. Segura E, Escobar-Mesa A, Grupo de Estudio Sobre la Enfermedad de Chagas. Epidemiología de la enfermedad de Chagas en el estado de Veracruz. Salud Pública Méx 2005;47:201-8.

20. Sanmartino M, Crocco L. Conocimientos sobre la enfermedad de Chagas y factores de riesgo en comunidades epidemiologicamente diferentes de Argentina. Rev Panam Salud Pública 2000;7:173-8.

21. Valente VC, Valente SA, Noireau F, Carrasco HJ, Miles MA. Chagas disease in the amazon basin: association of Panstrongylus geniculatus (Hemíptera, Reduviidae) with domestic pigs. J Med Entomol 1998;35:99-103.

22. D'Alessandro A, Barreto P, Thomas M. Nuevos registros de triatominos domiciliarios y extradomiciliarios en Colombia. Colombia Médica 1981;12:75-85.

23. Corredor A, Santacruz M, Gomez S, Guatame L. Distribución de los triatominos domiciliados en Colombia. Bogotá: Instituto Nacional de Salud; 1990.

24. Poyet G. Contexte écologique de Rhodnius pallescens (Heteroptera: Reduviidae) vecteur de la maladie de Chagas, dans son biotope natural, le palmera Attalea butyraceae: peuplement de l'entomofaune associée et estratégies adaptatives Rhodnius pallescens. Mémoire de maítrise de biologie des organismos et des populations. Paris: Université Pierre et Marie Curie; 1995.

25. Cárdenas J, Mazariego M. Anticuerpos antiTrypanosoma cruzi en pacientes con cardiomiopatía dilatada. Rev Med IMSS 2003;41:111-4.

26. Enciso C, Montilla M, Santacruz M, Nicholls S, Rodríguez A, Mercado M, et al. Comparación de la prueba de inmunofluorescencia indirecta, un inmunoensayo enzimático y la prueba comercial Chagatek ${ }^{\circledR}$ para la detección de anticuerpos antiTrypanosoma cruzi. Biomédica 2004;24:104-8.

27. GuhI F, Jaramillo C, Carranza JC, Vallejo GA. Molecular characterization and diagnosis of Trypanosoma cruzi and T. rangeli. Arch Med Res 2002;33:362-70.

28. Marcon GE, Andrade PD, de Alburquerque DM, Wanderley Jda S, de Almeida EA, Guariento ME, et al. Use of a nested polymerase chain reaction $(\mathrm{N}-$ PCR) to detect Trypanosoma cruzi in blood samples from chronic chagasic patients and patients' doubtful serologies. Diagn Microbiol Infect Dis 2002;43:39-43. 